\title{
Update on Mechanical Thrombectomy
}

Reuben Grech*

Medical Imaging Department, Mater Dei Hospital, Malta

*Corresponding author: Reuben Grech, 53/Flat 5, Resort Street, St. Paul's Bay, SPB 3200, Malta, Tel: 00356 79298235; E-mail: reubengrech@yahoo.com

Received date: May 27, 2015; Accepted date: June 24, 2015; Published date: June 27, 2015

Copyright: $\odot 2015$ Grech R. This is an open-access article distributed under the terms of the Creative Commons Attribution License, which permits unrestricted use, distribution, and reproduction in any medium, provided the original author and source are credited.

\section{Short Communication}

Intra-arterial stroke therapy aims to restore perfusion of the distal arterial bed by recanalizing the primary arterial occlusive lesion [1]. Successful recanalization positively correlates with improved longterm functional outcomes [2-4]. The PROACT II4 trial published in 1999 demonstrated a clear benefit from administering prourokinase via a catheter-based approach directly into the occlusive lesion.

Ever since then several intra-arterial approaches have been used which moved from intra-arterial administration of a thrombolytic agent to a mechanical approach in which the occlusive clot is either fragmented and aspirated or retrieved en-bloc.

SWIFT [5] and TREVO 2 [6] published in 2012 were randomised controlled trials which demonstrated the superiority of secondgeneration retrieval devices (stentrievers) as compared to the Merci device (a first-generation device). The studies also raised hope that an improvement in the prognosis of acute ischaemic stroke was achievable.

Mechanical thrombectomy was shown not to be superior to intravenous rt-PA in three randomised controlled studies published in the New England Journal of Medicine in 2013. The results of MR RESCUE [7], SYNTHESIS Expansion [8] and IMS III [9] were perhaps unexpected and though the trials may have had potential design flaws, they led to clinical equipoise surrounding the use of mechanical thrombectomy in stroke treatment. Some of the studies might have failed to demonstrate the superiority of mechanical thrombectomy due to an inaccurate evaluation of arterial recanalization by TIMI score after endovascular treatment [10-12]. Experts also argued that since these studies utilised mainly first-generation devices and were found to be equally effective as intravenous thrombectomy, then one would expect that second generation devices would be superior to standard treatment. This was however just a hypothesis and well-designed randomised trials were needed to confirm this.

MR CLEAN [13] enrolled 500 patients from 16 centres in the Netherlands. Within the mechanical thrombectomy arm, eligible patients were treated with intra-venous thrombolysis and thrombectomy up to 6 hours from symptom onset and stentrievers were utilised in $81.5 \%$ of cases. In the second arm, patients were treated with standard care alone. There was an absolute difference of 13.5 percentage points in the rate of functional independence ( $\mathrm{mRS} \leq$ 2 ) in favour of intervention ( $32.6 \%$ vs. $19.1 \%)$.

At the International Stroke Conference (ISC 2015) in Nashville three additional positive randomised controlled trials, namely ESCAPE [14], EXTEND-IA [15] and SWIFT PRIME [16] were presented.

ESCAPE [14] was a multi-centre collaboration trial which included 2 arms namely endovascular intervention and standard care versus standard care alone. Retrievable stents were used in $86 \%$ of cases within the thrombectomy arm. The primary outcome was a shift analysis of the modified Rankin score (mRS) which favoured the thrombectomy group with an odds ratio of 2.6. Similarly the endovascular group achieved a better rate of functional independence at 90 days.

EXTEND IA [15] which was set in Australia was stopped after 70 patients (out of the 100 planned initially) had been enrolled because of significant benefit in the endovascular arm. Patients treated with Solitaire and t-PA achieved a much better functional outcome (a secondary outcome of the trial) at 90 days.

SWIFT PRIME [16] demonstrated a significant difference $(\mathrm{p}=0.0002)$ in the rate of functional independence $(\mathrm{mRS} \leq 2)$ at 90 days between patients treated with intervention and intravenous thrombolysis $(60 \%)$ versus those treated with standard care alone (35\%). The trial recruited 196 patients from 61 centres and intervention was performed using the Solitaire device.

Following these trials the European Society of Neuroradiology (ESNR) together with the European Stroke Organisation (ESO) and the European Society on Minimal Invasive Neurological Therapy (ESMINT) issued a consensus statement on the use of mechanical thrombectomy in acute ischaemic stroke. Although this consensus was not a guideline as such, it promoted the use of intra-arterial therapy and will act as a strong support for new guidelines for stroke therapy.

At the European Stroke Organisation (ESO 2015) meeting in Glasgow, REVASCAT [17], an additional positive randomised controlled trial on stroke treatment was presented. 206 patients were included in the trial performed in 4 centres in Spain. The thrombectomy arm utilised the Solitaire device and patients within this arm were also administered intravenous thrombolysis. Patients within the second arm of the trial were treated with standard medical care alone. The rates of functional independence at 90 days were $44 \%$ and $28 \%$ in the mechanical thrombectomy and standard care arms respectively with an odds ratio of 2.0 in favour of the former.

The publication of this positive data from 5 different randomised controlled trials confirms that endovascular treatment is highly beneficial and this should remove any scepticism surrounding the use of mechanical thrombectomy in acute stroke. It is also crucial to note the excellent functional outcomes achieved in these trials. $60 \%$ of acute stroke patients managed to achieve functional independence at 90 days in SWIFT PRIME [16] which promises a better prognosis for acute stroke patients.

The difference in the rates of functional independence in the 5 trials ranged from 13.5 to 31 percentage points which translates into a number needed to treat (NNT) as low as three patients for benefit [18]. The odds ratios of the treatment effect demonstrated in the recent randomised controlled studies are summarised in Figure 1. The overall odds ratio in favour of mechanical thrombectomy is $2.4(\mathrm{p}=0.000)$. 
Page 2 of 3

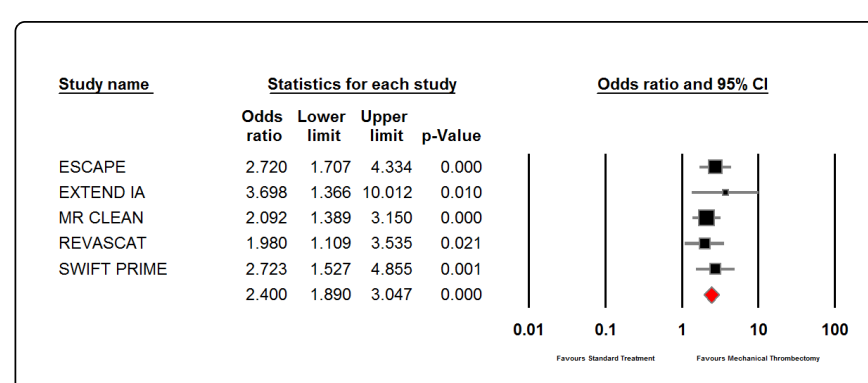

Figure 1: Odds ratios of treatment effect

Importantly these studies also confirmed that there were no significant differences in the rates of mortality and symptomatic intracranial haemorrhage between patients treated with mechanical thrombectomy versus those treated with standard care alone. This also proves that mechanical thrombectomy is a safe precedure with a similar rate of adverse events to standard care.

Mechanical thrombectomy is often performed under local anaesthesia once an arterial occlusive lesion is confirmed. The occluding thrombus is entrapped between the stent struts and the vessel wall once the stent retriever is deployed. This allows an almost immediate restoration of blood flow. As opposed to conventional stents, stentrievers allow thrombectomy to be performed as the stent is retracted back within the micro-catheter. The retrievable stents can also be applied repeatedly until satisfactory flow restoration is achieved.

\begin{tabular}{|c|c|c|}
\hline \multicolumn{3}{|c|}{ Recommendations on Patient Selection* } \\
\hline 1 & $\begin{array}{l}\text { Intracranial vessel occlusion must be diagnosed with non- } \\
\text { invasive imaging whenever possible before considering } \\
\text { treatment with mechanical thrombectomy. }\end{array}$ & $\begin{array}{l}\text { (Grade A, Level } \\
\text { 1a, KSU Grade } \\
\text { A) }\end{array}$ \\
\hline 2 & $\begin{array}{l}\text { If vessel imaging is not available at baseline, a NIHSS } \\
\text { score of } \geq 9 \text { within three, and } \geq 7 \text { points within six hours } \\
\text { may indicate the presence of large vessel occlusion. }\end{array}$ & $\begin{array}{l}\text { (Grade B, Level } \\
\text { 2a, KSU Grade } \\
\text { B) }\end{array}$ \\
\hline 3 & $\begin{array}{l}\text { Patients with radiological signs of large infarcts (for ex. } \\
\text { using the ASPECTS score) may be unsuitable for } \\
\text { thrombectomy. }\end{array}$ & $\begin{array}{l}\text { (Grade B, Level } \\
\text { 2a, KSU Grade } \\
\text { B) }\end{array}$ \\
\hline 4 & $\begin{array}{l}\text { Imaging techniques for determining infarct and penumbra } \\
\text { sizes can be used for patient selection and correlate with } \\
\text { functional outcome after mechanical thrombectomy. }\end{array}$ & $\begin{array}{l}\text { (Grade B, Level } \\
\text { 1b, KSU Grade } \\
\text { B) }\end{array}$ \\
\hline 5 & $\begin{array}{l}\text { High age alone is not a reason to withhold mechanical } \\
\text { thrombectomy as an adjunctive treatment. }\end{array}$ & $\begin{array}{l}\text { (Grade A, Level } \\
\text { 1a, KSU Grade } \\
\text { A) }\end{array}$ \\
\hline \multicolumn{3}{|c|}{$\begin{array}{l}\text { *Adapted from 'Consensus statement on mechanical thrombectomy in acute } \\
\text { ischemic stroke' - ESO-Karolinska Stroke Update } 2014 \text { in collaboration with } \\
\text { ESMINT and ESNR. }\end{array}$} \\
\hline
\end{tabular}

Table 1: Recommendations on patient selection

Patient selection [19] and timely intervention were shown to be crucial factors that influence functional outcome in acute stroke patients. The updated recommendations on patient selection for mechanical thrombectomy in acute ischaemic stroke are summarised in Table 1 . The newer stent-based retriever devices were likely responsible for the improved functional outcomes in the 5 trials as they are able to achieve a faster and more complete recanalization.

Many stroke centres were already performing mechanical thrombectomy prior to the publication of these trials. The new data that emerged supports this treatment and clinical equipoise does no longer exist. Stroke guidelines should therefore be modified to include mechanical thrombectomy as part of the multi-modal approach in acute ischaemic stroke treatment.

\section{References}

1. Tomsick T (2007) TIMI, TIBI, TICI: I came, I saw, I got confused. AJNR Am J Neuroradiol 28: 382-384.

2. Rha JH, Saver JL (2007) The impact of recanalization on ischemic stroke outcome: a meta-analysis. Stroke 38: 967-973.

3. Nogueira RG, Yoo AJ, Buonanno FS, Hirsch JA (2009) Endovascular approaches to acute stroke, part 2: a comprehensive review of studies and trials. AJNR Am J Neuroradiol 30: 859-875.

4. Furlan A, Higashida R, Wechsler L, Gent M, Rowley H, et al. (1999) Intra-arterial prourokinase for acute ischemic stroke. The PROACT II study: a randomized controlled trial. Prolyse in acute cerebral thromboembolism JAMA 282: 2003-2011.

5. Saver JL, Jahan R, Levy EI, Jovin TG, Baxter B, et al. (2012) The SWIFT Trialists. SOLITAIRE ${ }^{m}$ with the intention for thrombectomy (SWIFT) trial: design of a randomized, controlled, multicenter study comparing the SOLITAIRE ${ }^{\mathrm{m}}$ Flow Restoration device and the MERCI Retriever in acute ischaemic stroke. Int J Stroke 9: 658-668.

6. Nogueira RG, Lutsep HL, Gupta R, Jovin TG, Albers GW, et al. (2012) Trevo versus Merci retrievers for thrombectomy revascularisation of large vessel occlusions in acute ischaemic stroke (TREVO 2): a randomised trial. Lancet 380: 1231-1240.

7. Kidwell CS, Jahan R, Gornbein J, Alger JR, Nenov V, et al. (2013) A trial of imaging selection and endovascular treatment for ischemic stroke. N Engl J Med 368: 914-923.

8. Ciccone A, Valvassori L, Nichelatti M, Sgoifo A, Ponzio M, et al. (2013) Endovascular treatment for acute ischemic stroke. N Engl J Med 368: 904-913.

9. Broderick JP, Palesch YY, Demchuk AM, Yeatts SD, Khatri P, et al. (2013) Endovascular therapy after intravenous t-PA versus t-PA alone for stroke. N Engl J Med 368: 893-903.

10. Tomsick T (2007) TIMI, TIBI, TICI: I came, I saw, I got confused. AJNR Am J Neuroradiol 28: 382-384.

11. Bar M, Mikulik R, Jonszta T, Krajina A, Roubec M, et al. (2012) Diagnosis of recanalization of the intracranial artery has poor inter-rater reliability. AJNR Am J Neuroradiol 33: 972-974.

12. Schellinger PD, Hacke W (2010) Recanalization devices should be restricted to clinical trials: pro (kind of). Stroke 41: 191-193.

13. Berkhemer OA, Fransen PS, Beumer D, van den Berg LA, Lingsma HF, et al. (2015) A randomized trial of intraarterial treatment for acute ischemic stroke. N Engl J Med 372: 11-20.

14. Goyal M, Demchuk AM, Menon BK, Eesa M, Rempel JL, et al. (2015) Randomized assessment of rapid endovascular treatment of ischemic stroke. N Engl J Med 372: 1019-1030.

15. Campbell BC, Mitchell PJ, Kleinig TJ, Dewey HM, Churilov L, et al. (2015) Endovascular therapy for ischemic stroke with perfusion-imaging selection. N Engl J Med 372: 1009-1018.

16. Saver JL, Goyal M, Bonafe A, Diener HC, Levy EI, et al. (2015) Stentretriever thrombectomy after intravenous t-PA vs. $t-\mathrm{PA}$ alone in stroke. N Engl J Med 372: 2285-2295.

17. Jovin TG, Chamorro A, Cobo E, de Miquel MA, Molina CA, et al. (2015) Thrombectomy within 8 hours after symptom onset in ischemic stroke. N Engl J Med 372: 2296-2306.

18. Furlan AJ (2015) Endovascular Therapy for Stroke - It's about Time. N Engl J Med. 
Citation: Grech R (2015) Update on Mechanical Thrombectomy. J Neurol Neurophysiol 6: 297. doi:10.4172/2155-9562.1000297

Page 3 of 3

19. Grech R, Galvin PL, Power S, O'Hare A, Looby S, et al. (2014) Outcome prediction in acute stroke patients considered for endovascular treatment: a novel tool. Interv Neuroradiol 20: 312-324. 